\title{
Sleep Deprivation Causes Behavioral, Synaptic, and Membrane Excitability Alterations in Hippocampal Neurons
}

\author{
Carmel M. McDermott, ${ }^{1}$ Gerald J. LaHoste,,${ }^{1,2}$ Chu Chen, ${ }^{1}$ Alberto Musto, ${ }^{1}$ Nicolas G. Bazan, ${ }^{1}$ and Jeffrey C. Magee ${ }^{1}$ \\ ${ }^{1}$ Neuroscience Center, Louisiana State University Health Science Center, New Orleans, Louisiana 70115, and 2 Psychology Department, University of New \\ Orleans, New Orleans, Louisiana 70148
}

\begin{abstract}
Although the function of sleep remains elusive, several lines of evidence suggest that sleep has an important role in learning and memory. In light of the available data and with the prevalence of sleep deprivation (SD), we sought to determine the effect of SD on neuronal functioning. We found that the exposure of rats to $72 \mathrm{hr}$ of primarily rapid eye movement SD impaired their subsequent performance on a hippocampus-dependent spatial learning task but had no effect on an amygdala-dependent learning task. To determine the underlying cellular level mechanisms of this hippocampal deficit, we examined the impact of SD on several fundamental aspects of membrane excitability and synaptic physiology in hippocampal CA1 pyramidal neurons and dentate gyrus granule cells. We found that neuronal excitability was severely reduced in CA1 neurons but not in granule cells and that the production of long-term potentiation of synaptic strength was inhibited in both areas. Using multiple SD methods we further attempted to differentiate the effects of sleep deprivation from those associated with the nonspecific stress induced by the sleep deprivation methods. Together these data suggest that failure to acquire adequate sleep produces several molecular and cellular level alterations that profoundly inhibit hippocampal functioning.
\end{abstract}

Key words: sleep deprivation; stress; hippocampus; LTP; membrane excitability; spike frequency adaptation; memory

\section{Introduction}

Several lines of evidence suggest that sleep has a key role in learning and memory (for review, see Maquet, 2001; Siegel, 2001; Stickgold et al., 2001; Pace-Schott and Hobson, 2002). For example, the percentage of time spent in rapid eye movement (REM) sleep is increased after certain learning tasks (Smith and Lapp, 1986; Mandai et al., 1989), and if REM sleep is prevented after the training, the subsequent performance of this task is impaired (Karni et al., 1994; Smith, 1995). Deprivation of sleep before task training also impairs performance in many behavioral tasks (Stern, 1971). Furthermore, neuronal ensembles that were active during a previous learning experience are reactivated during sleep (Wilson and McNaughton, 1994; Skaggs and McNaughton, 1996; Louie and Wilson, 2001), suggesting that memory consolidation may actually occur during sleep. At a cellular level, changes in synaptic efficacy and membrane excitability are thought to be critical for the formation of memories (Bliss and Collingridge, 1993), and there have been some suggestions that these neuronal properties could be altered during sleep and by the lack of sleep (Buzsaki, 1998; Graves et al., 2001). Finally, sleep deprivation (SD) is known to delay developmentally regulated plasticity in the visual cortex, again signifying a relationship between sleep and neuronal plasticity (Schaffery et al., 2002).

Given the well recognized cognitive effects and the prevalence

Received June 23, 2003; revised June 23, 2003; accepted Aug. 29, 2003.

This work was supported by United States Department of Defense Grant DAAD19-02-1-0042. We thank K. Brandon Cline and Isabel M. Billiot for their excellent technical assistance.

Correspondence should be addressed to Jeffrey C. Magee, Neuroscience Center, Louisiana State University Health Science Center, 2020 Gravier Street, New Orleans, LA 70112. E-mail: jmagee@|suhsc.edu.

Copyright $\odot 2003$ Society for Neuroscience $\quad$ 0270-6474/03/239687-09\$15.00/0 of sleep deprivation in society today, a determination of the impact of SD on cellular physiology is of interest. Here we began by assessing the impact of SD on hippocampus-dependent contextual and amygdala-mediated cued memory (Kim and Fanselow, 1992; Phillips and LeDoux, 1992); we then followed this with an examination of the effects of SD on synaptic plasticity and neuronal excitability in principal neurons of the hippocampus, an area crucial to the formation and encoding of memories. We have found that $72 \mathrm{hr}$ SD produces severe behavioral deficits that may be linked to particular cellular level alterations in membrane excitability and synaptic plasticity within the hippocampus.

\section{Materials and Methods}

Subjects were 7- to 9-week-old male Sprague Dawley rats, and all experiments were performed within the guidelines of the Louisiana State University Health Science Center Institutional Animal Care and Use Committee.

Sleep deprivation. In initial experiments, the single small platform (SP) technique of sleep deprivation was used. Rats were placed on a single platform $(6.2 \mathrm{~cm}$ diameter $)$ in the middle of a water tank. The water reached up to $\sim 2 \mathrm{~cm}$ below the surface of the platform. Food and water were available ad libitum. In subsequent experiments, additional SD chambers were used to control for non-SD-related effects. In the single large platform (LP) technique, the size of the platform was increased to a diameter of $15.2 \mathrm{~cm}$ to allow sleep to occur. In the multiple small platforms (MPs) technique, five platforms, each of $6.2 \mathrm{~cm}$ diameter, were used. Platforms were spaced $(8-10 \mathrm{~cm}$ apart) so that rats could easily move between them but could not lie across any two. All treatments lasted $72 \mathrm{hr}$. Control rats were housed in their home cages.

Electroencephalogram recording. Electroencephalogram (EEG) recordings were obtained to determine the level and type of sleep deprivation experienced on each of the three devices. Bipolar electrodes (Plastic One Inc.) were implanted in the right hippocampal CA1 field [anteroposteri- 
or (AP) $5.3 \mathrm{~mm}$; lateral (L-L) $3 \mathrm{~mm}$; dorsoventral (DV) $3.1 \mathrm{~mm}$ from bregma] and in the left parietal cortex (AP $2.8 \mathrm{~mm}$; L-L $5 \mathrm{~mm}$; DV $3 \mathrm{~mm}$, from bregma), and another was implanted in the neck muscles. After a $3 \mathrm{~d}$ recovery period, EEG signals were amplified and digitized using Enhanced Graphics Acquisition software (RC Electronics) for a $24 \mathrm{hr}$ control period that was then followed by placement on one of the small, multiple, or large platform devices for $3 \mathrm{~d}$ with continuous EEG recordings. The average time per stage (non-REM, REM, or awake) was calculated using parameters, previously configured, in Matlab and Neuroexplorer software. Animals were considered awake if the EEG showed low-voltage, high-frequency activity and sustained neck muscle tone. They were considered to be in nonREM if the EEG showed high-amplitude, low-frequency activity combined with low muscle tone. Finally, REM sleep was determined to be present when the EEG showed moderate amplitude signals with a prominent theta-wave presence $(5-10 \mathrm{~Hz})$ and low muscle tone. We found that when rats were placed on a small platform, the EEGs showed the rats to be awake $\sim 87 \%$ of the time, $\sim 12 \%$ in non-REM, and $<1 \%$ in REM. Similar proportions were observed when the rats were placed on multiple small platforms ( $\sim 76 \%$ awake, $\sim 23 \%$ non-REM, $<1 \%$ REM). When placed on the large platform, however, the EEGs showed very different proportions of sleep-wake states (47\% awake, 33\% non-REM, $20 \%$ REM) that were more similar to the control recording periods ( $\sim 50 \%$ awake, $\sim 35 \%$ non-REM, $\sim 15 \%$ REM). These recordings confirm that both the SP and MP devices produce a severe REM sleep deprivation but still allow a significant amount of slow-wave sleep to occur. Furthermore, the LP device appears to allow the rats to achieve a relatively normal level of REM sleep.

Test of contextual versus cued memory. Freezing behavior was conditioned by placing a rat in an operant conditioning chamber with a grid floor. After a 3 min period, three 2 min blocks of tone-shock pairings were administered as follows: a tone $(80 \mathrm{~dB})$ was presented for $30 \mathrm{sec}$; at the termination of the tone, a $2 \mathrm{sec}$ foot shock was administered $(0.8 \mathrm{~mA})$; an $88 \mathrm{sec}$ intertrial interval occurred during which no shock or tone was administered. After three tone-shock pairings the animal was returned to its home cage. Twenty-four hours after conditioning the animal was placed in the same operant chamber as above for $6 \mathrm{~min}$, during which no tone or shock was presented. Freezing behavior, which in this setting is indicative of contextual memory, was recorded as present or absent for each $10 \mathrm{sec}$ interval. Because of nonhomogeneity of variance between groups, raw data summed across the 6 min testing interval were converted to ranks and subjected to a Kruskal-Wallis ANOVA. Two hours after the test of contextual memory, the animal was placed in a novel chamber, which differed from the conditioning chamber by shape, texture, color, and complexity. After $3 \mathrm{~min}$, the conditioning tone was presented once for $30 \mathrm{sec}$, and the animal was left in the chamber for another $2.5 \mathrm{~min}$. Freezing behavior after the tone, indicative of cued memory, was scored as described above. Previous research has shown that the neural processes underlying contextual memory are mediated primarily via the hippocampus, whereas those underlying cued memory are mediated by several structures, most prominently the amygdala (Kim and Fanselow, 1992; Phillips and LeDoux, 1992).

In vitro electrophysiology. Hippocampal slices $(400 \mu \mathrm{m})$ were prepared using standard procedures that have been described previously (Magee, 1998). Individual neurons were visualized with a Zeiss Axioskop fit with differential interference contrast (DIC) optics using infrared illumination. All neurons exhibited resting membrane potentials between -63 and $-75 \mathrm{mV}$. Whole-cell patch-clamp recordings were made using either a Dagan BVC-700 or an Axoclamp-2B amplifier in "bridge" mode. Data were acquired at $10 \mathrm{kHz}$ and filtered at $1 \mathrm{kHz}$. The normal external recording solution contained (in $\mathrm{mm}$ ): $124 \mathrm{NaCl}, 2.5 \mathrm{KCl}, 1.2 \mathrm{NaH}_{2} \mathrm{PO}_{4}$, $25 \mathrm{NaHCO}_{3}, 2.0 \mathrm{CaCl}_{2}, 1.0 \mathrm{MgCl} 2$, and 10 dextrose, bubbled with $95 \%$ $\mathrm{O}_{2} / 5 \% \mathrm{CO}_{2}$ at $\sim 35^{\circ} \mathrm{C}, \mathrm{pH}$ 7.4. Whole-cell recording pipettes (somatic, 2-4 $\mathrm{M} \Omega$; dendritic, 5-7 M $\Omega$ ) were pulled from borosilicate glass. For membrane excitability characterization, the internal pipette solution consisted of (in mM): $120 \mathrm{KMeSO}_{4}, 20 \mathrm{KCl}, 10 \mathrm{HEPES}, 0.05$ EGTA, 4.0 $\mathrm{Mg}_{2} \mathrm{ATP}, 0.3 \mathrm{Tris}_{2} \mathrm{GTP}, 14$ phosphocreatine, and $4 \mathrm{NaCl}$, pH 7.25 with KOH. For whole-cell long-term potentiation (LTP) experiments, 120 mu KGluconate replaced the KMeSO4. Series resistance for somatic recordings was 6-30 M $\Omega$, whereas that for dendritic recordings was $15-40$
$\mathrm{M} \Omega$. Voltages have not been corrected for the theoretical liquid junction potential $(\sim 7 \mathrm{mV})$. For field recordings the external solution contained (in mM): $125 \mathrm{NaCl}, 2.5 \mathrm{KCl}, 1.35 \mathrm{NaH}_{2} \mathrm{PO}_{4}, 25 \mathrm{NaHCO}_{3}, 2.5 \mathrm{CaCl}_{2}, 1.3$ $\mathrm{MgCl}$, and 25 dextrose. Pipettes (2-4 M $\Omega$ ) were filed with external solution. Final concentrations of bicuculline $(10 \mu \mathrm{M})$ were made daily from stock solutions dissolved in DMSO. Error bars represent SEM, and the number of cells $(n)$ is given.

A bipolar tungsten stimulating electrode was placed in the middle of stratum radiatum within $75 \mu \mathrm{m}$ of the recorded cell for whole-cell CA1 LTP experiments and within $200 \mu \mathrm{m}$ of the recording electrode in the field experiments. For perforant-path LTP, the stimulating electrode was placed in the middle of the molecular layer $\sim 200 \mu \mathrm{m}$ from the recorded cell. Baseline EPSPs were recorded in response to stimulation of the respective pathway at a frequency of $0.05 \mathrm{~Hz}$. The amplitude range of the evoked EPSPs was adjusted to $4-7 \mathrm{mV}$ ( $<30 \%$ of threshold for generating an action potential). LTP in the perforant path was induced by highfrequency stimulation (consisting of eight trains, each of eight pulses at $200 \mathrm{~Hz}$ with an intertrain interval of $2 \mathrm{sec}$ ) paired with postsynaptic depolarizing current injection $(0.6 \mathrm{nA})$. Schaffer collateral LTP in wholecell recordings was induced by theta-type synaptic stimuli (two trains of five bursts consisting of five stimuli at $100 \mathrm{~Hz}$ separated by $200 \mathrm{msec}$ with $30 \mathrm{sec}$ between trains) paired with enough postsynaptic depolarizing current to evoke at least three action potentials per burst $(0.4-0.8 \mathrm{nA})$ (Magee and Johnston, 1997). In field recordings, paired-pulse stimulation was performed using two pulses, each of $0.1 \mathrm{msec}$ duration and 50 msec apart. The amplitude used for the first pulse was approximately half of maximum. LTP was induced with two $100 \mathrm{~Hz}$ stimulus trains of $1 \mathrm{sec}$ duration at threshold stimulus with a $30 \mathrm{sec}$ interval. For long-term depression (LTD), 900 pulses at test stimulus intensity were given at a frequency of $3 \mathrm{~Hz}$. A stable baseline was maintained for $10 \mathrm{~min}$ before either LTP or LTD induction, and recordings were made for $30 \mathrm{~min}$ after.

Corticosterone radioimmunoassay. Plasma corticosterone levels were assessed using radioimmunoassay (ICN Biomedicals). Samples were collected in EDTA at time of perfusion and centrifuged at $1000 \mathrm{rpm}$ for 10 $\min$ at $4^{\circ} \mathrm{C}$, and plasma was then frozen until the day of the assay.

\section{Results \\ Impact of sleep deprivation on contextual versus cued memory}

To test for the impact of SD on memory formation, a group of rats were sleep deprived for $72 \mathrm{hr}$ using the SP method, whereas a second set of animals were maintained in their home cages during this time (control). After the $72 \mathrm{hr}$ period, each group of rats was trained in an operant conditioning chamber according to the protocol detailed in Materials and Methods. As expected, control rats displayed freezing behavior on the test day in the context in which they were previously shocked, indicative of intact hippocampal-mediated memory. By contrast, SP rats showed $88 \%$ less freezing than did control rats, indicative of significant and severe memory impairment $(H=10.79$; $\mathrm{df}=1 ; p<0.001)$. When tested for cued memory, both control and SP rats displayed significant freezing behavior on the test day in response to the cue, indicative of intact amygdala-mediated memory. It thus appears that $72 \mathrm{hr}$ sleep deprivation, before the training session, greatly impaired the abilities of the rats to form new contextual memories when compared with control animals (Fig. 1), whereas their ability to form cued memories appeared to be completely intact.

\section{Cellular mechanisms of SD-induced behavioral deficits Membrane excitability}

We next turned to in vitro recording techniques to examine the impact of SD on the membrane excitability and synaptic plasticity of CA1 pyramidal and dentate gyrus (DG) granule cells in hippocampal slices. Using whole-cell patch-clamp recordings from hippocampal CA1 pyramidal neurons, we initially com- 


\section{A. Contextual Memory}

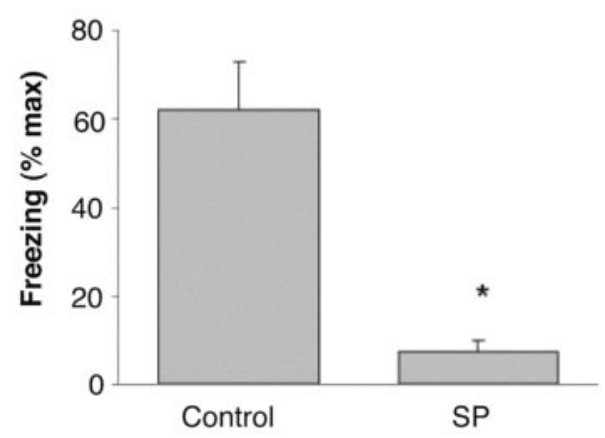

\section{B. Cued Memory}

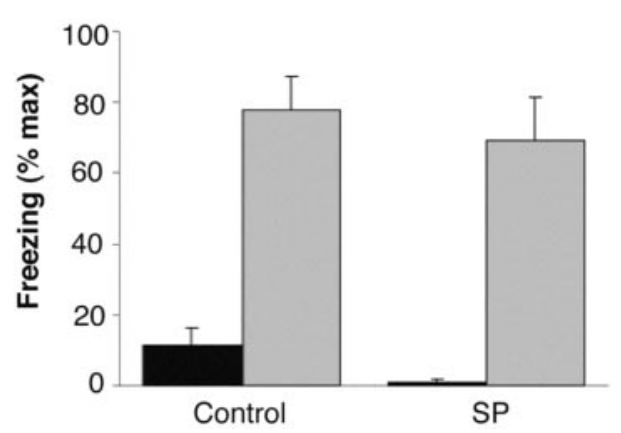

Figure 1. Effects of $72 \mathrm{hr}$ SD on hippocampus-mediated $(A)$ and amygdala-mediated $(B)$ memory. Y-axes show the mean ( \pm SEM) amount of freezing as percentage of maximum (\% $\max )$ possible for each group. $A$, Freezing in the context in which tone--shock pairings occurred $24 \mathrm{hr}$ before test was normal in controls $(n=9)$ but significantly $\left({ }^{*} p<0.001\right)$ reduced in rats that were sleep deprived for $72 \mathrm{hr}$ by the single small platform method $(n=9)$. (Data were collapsed over the 6 min test period, during which no tones or shocks were delivered.) $B$ Freezing in a novel environment before (black bars) and after (gray bars) presentation of the cue (tone) that had been paired previously with shock was equivalent between control and SP rats. No shock was presented during this test.

pared the number of action potentials produced by 700 -mseclong depolarizing current injections in neurons from control and $\mathrm{SD}$ rats. Frequency-current plots showed that the number of spikes evoked by any given current injection was reduced to approximately half in neurons from SD rats when compared with control (Fig. 2 B, Table 1). Although spike firing was reduced in SD neurons, we did not observe any differences in action potential threshold, amplitude or duration between the groups (Table 1). Furthermore, the amplitude and duration of spike afterhyperpolarizations (AHPs) after single action potentials (fast and medium AHPs) were similar in amplitude and duration in SD neurons (Table 1). Although most action potential properties appeared relatively normal, a difference in the pattern of spike firing during prolonged depolarization was obvious, with SD neurons showing an approximately twofold increase in spike frequency adaptation when compared with control (Fig. 2, Table 1). We next calculated membrane input resistance $\left(R_{\text {in }}\right)$ from voltage deflections produced by a series of $700 \mathrm{msec}$ mainly hyperpolarizing current injections. The slope of current-voltage plots showed that $R_{\text {in }}$ was reduced by $\sim 25 \%$ in the SD group of neurons (Fig. $2 D$, Table 1). Resting membrane potential $\left(V_{\mathrm{m}}\right)$, measured as the initial potential recorded after membrane patch rupture, was unchanged in SD neurons (Table 1). Together these data indicate that, after $72 \mathrm{hr}$ of REM SD, the overall membrane excitability of CA1 pyramidal neurons is significantly reduced by the presence of a lower $R_{\text {in }}$ and an enhanced spike frequency adaptation. Whole-cell recordings from dentate granule cells showed no significant differences in membrane excitability $\left(R_{\text {in }}\right.$ for control, $179 \pm 13 \mathrm{M} \Omega$; SD, $176 \pm 18 \mathrm{M} \Omega$ ).

Recordings from the apical dendritic arbor of CA1 pyramidal neurons revealed that a similar modification of membrane excitability is widespread throughout many regions of these cells. We found that although action potential back-propagation was normal (amplitude, frequency dependence, and amplitude boosting), both input resistance (reduced by $30 \%$ ) and action potential duration (reduced by $42 \%$ ) were altered in a manner consistent with the somatic recordings (Table 2) (Magee 1998).

\section{Synaptic physiology}

To investigate the effect of SD on synaptic properties, Schaffer collateral synaptic input to CA1 pyramidal neurons was examined using both field potential and somatic whole-cell voltage recordings. For middle ( $\sim 200 \mu \mathrm{m}$ from the cell body layer) Schaffer collateral stimulation, most basic field and whole-cell EPSP properties were unaltered in neurons from SD rats. For example, field potential amplitudes at 50\% maximum, intracellular EPSP rise times, and paired-pulse facilitation were not changed after SD (Table 3). On the other hand, intracellular EPSP half-width was slightly reduced, but this presumably reflects the lower $R_{\text {in }}$ in these cells and not any significant change in synaptic properties (Table 3 ).

Although single EPSPs and short-term plasticity appeared quite normal after SD, the magnitude of LTP as measured $30 \mathrm{~min}$ after two different induction protocols (see Materials and Methods) was severely reduced in both CA1 pyramidal neurons and DG granule cells located in slices from sleep-deprived animals. In field recordings from area CA1, $1 \mathrm{sec}$ duration $100 \mathrm{~Hz}$ tetani produced a mean potentiation in slices from SD rats of $6.4 \pm 5.5$ versus $45.9 \pm 4.1 \%$ in control $(p<0.001)$ (Fig. 3). Likewise, mean potentiation in whole-cell recordings after a theta-type induction protocol was $22 \pm 16 \%$ in neurons from SD rats compared with $89 \pm 19 \%$ in control. In whole-cell recordings from dentate granule neurons, SD also inhibited the induction of LTP by a theta-type protocol given to both medial and lateral perforant paths (SD $46 \pm 15 \%$ vs control $102 \pm 20.1 \%$ ) (Fig. 3). Because of the potential importance of action potential generation in LTP induction, the level of somatic current injection into CA1 pyramidal was manipulated to ensure that the same numbers of action potentials were initiated in all groups (three to four spikes per burst in CA1; see Materials and Methods). Such manipulations were not necessary in the DG granule cells because they showed no alterations in membrane excitability.

Although LTP was clearly inhibited, LTD of Schaffer collateral synapses induced by $5 \mathrm{~min}$ of $3 \mathrm{~Hz}$ stimuli appeared normal (control $13.7 \pm 5.5 \%$ vs SD $18.1 \pm 3.4 \%$ depression at $30 \mathrm{~min}$ after tetanus) (Fig. $4 A$ ). Also, the induction of LTD could not rescue the LTP in neurons from SD rats, because giving $100 \mathrm{~Hz}$ tetani 30 min after LTD induction had no effect on the amount of LTP produced (Fig. 4 B). Finally, a $24 \mathrm{hr}$ recovery period after the $72 \mathrm{hr}$ SD was sufficient for complete reversal of the sleep deprivation-induced inhibition of LTP $(52.6 \pm 9.8 \%$ potentiation) (Fig. 4C). Therefore, the deprivation of sleep does not appear to simply cause a reduction in cell or synapse viability, because many basic properties including those of the action potential and other forms of synaptic plasticity are all unaffected. 
Furthermore, all cellular properties examined return to control levels after a short recovery period.

\section{Impact of platform-related effects \\ Devices}

There is little doubt that the small platform method of sleep deprivation produces results that are specific for SD and others that are not. One potential nonspecific effect is a chronic immobilization stress response, and another could be some poorly defined nonspecific platform effect that is not necessarily related to immobilization stress (e.g., water aversion). To control for these nonspecific effects we also tested the impact of a chamber containing a single platform that is large enough for the rats to sleep on but not large enough for them to walk around on (LP). A third chamber contained five small platforms that are spaced closely enough to allow the rats to walk around but not close enough for them to acquire any significant levels of REM sleep (MPs). Because the animals can move from platform to platform within the multiple platforms chamber, this device has been reported to produce less immobilization stress compared with either single platform device, whereas all of the immobilization stress as well as other nonspecific platform effects are fully present in the LP devices (Coenen and Van Luijtelaar, 1985). Therefore, the LP device should produce whatever alterations result from immobilization stress and nonspecific platform effects, whereas the MP device should produce a less immobilization stressful form of sleep deprivation.

\section{Membrane excitability}

Examination of the membrane properties under these additional treatments revealed a distinguishable nonspecific platform effect. The $R_{\text {in }}$ of neurons from rats confined to the LP device for $72 \mathrm{hr}$ was significantly lower than that of controls $(49.3 \pm 1.5$ vs $70.4 \pm 2.1 \mathrm{M} \Omega ; p>0.05)$ and was not different from that of cells from rats placed on single small platforms. Consistent with this being primarily an immobilization stress response, cells from MP rats had normal $R_{\text {in }}$ relative to control animals $(66.4 \pm 2.0 \mathrm{M} \Omega)$. Thus, the isolated induction of persistent long-term immobilization stress by the large platform appeared to reduce the $R_{\text {in }}$ of CA1 pyramidal neurons more than the sleep deprivation produced by the MP devices (compare LP versus MP) (Fig. 2).

Because of the numerous factors involved in shaping spikefiring patterns, the relative roles of sleep deprivation and stress in the alteration of those patterns was less straightforward. We saw that the number of spikes evoked during prolonged depolarization was reduced in all test groups, with the greatest effect obparentheses.
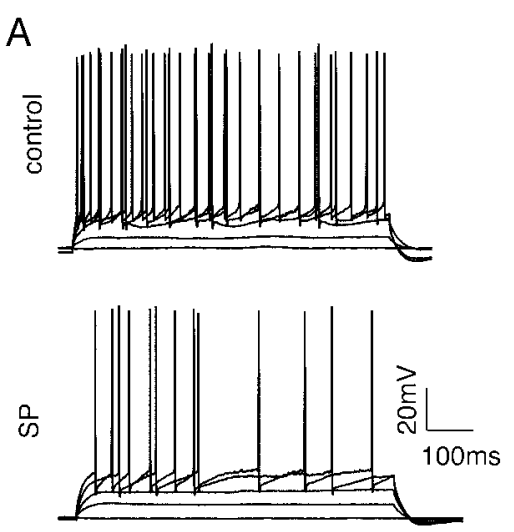

B
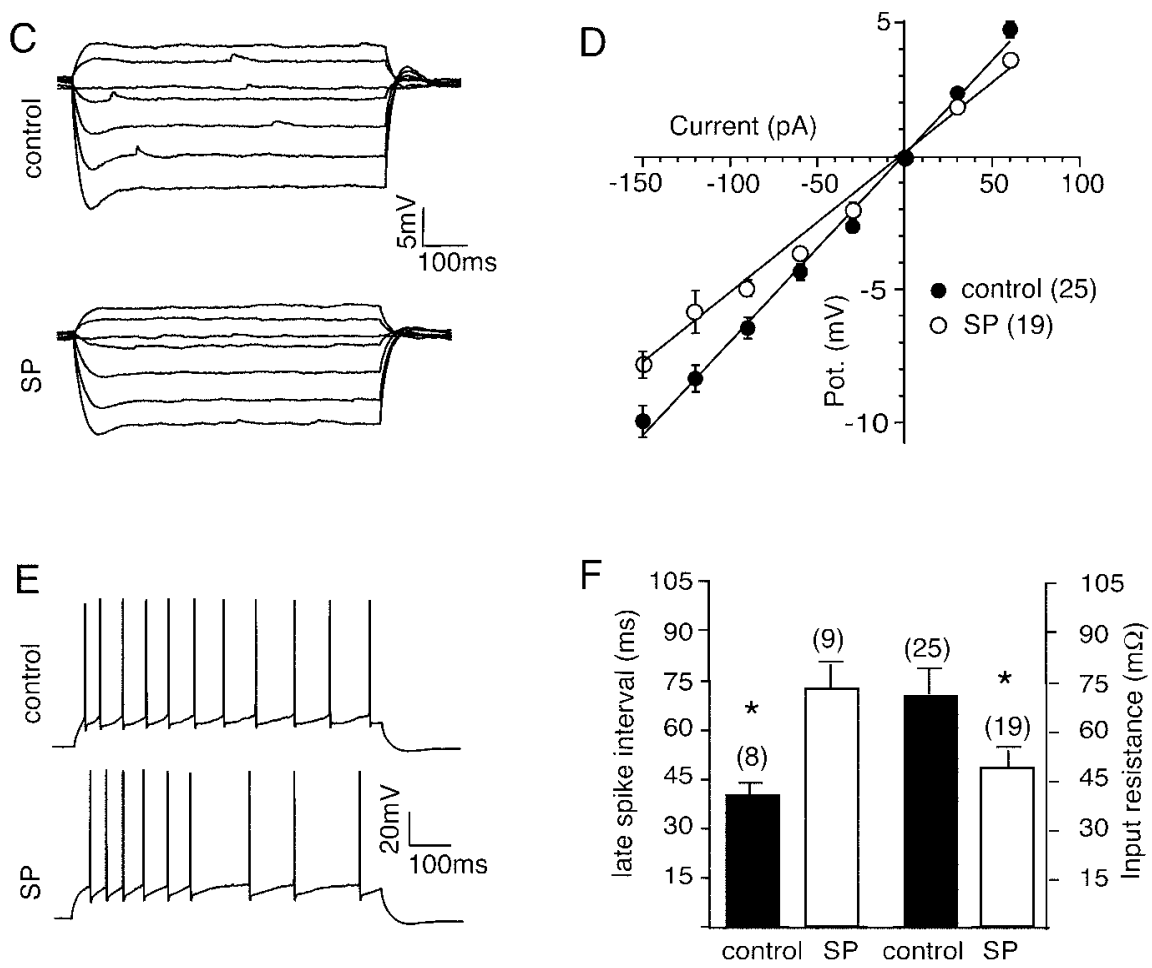

Figure 2. Neuronal excitability is reduced after sleep deprivation. $A$, Frequency of firing is dramatically reduced after sleep deprivation. Membrane potential in response to current injections ranging from 0 to $350 \mathrm{pA}$ (top) for control and 0 to $400 \mathrm{pA}$ for SP (bottom). B, Summary frequency - current plot shows that firing is markedly reduced in the SP group compared with controls. C, Membrane potential in response to current injections ranging from -210 to $60 \mathrm{pA}$ ( $30 \mathrm{pA}$ steps) for control (top) and SP neurons (bottom).D, Summary current-voltage plots showing that $R_{\text {in }}$ is reduced in SP neurons. E, Spike frequency adaptation is enhanced in SP neurons. Representative traces showing membrane potential from a control (top) and an SP neuron (bottom) in response to $300 \mathrm{pA}$ current injections to both cells. F, Summary plots of adaptation (mean interval for spikes in the final $350 \mathrm{msec}$ of the current step) and input resistance. The SP group has an enhanced adaptation and reduced input resistance compared with the control group. To normalize for the differences in $R_{\text {in }}$, mean intervals were calculated from $350 \mathrm{pA} \mathrm{injections} \mathrm{in} \mathrm{the} \mathrm{control} \mathrm{group} \mathrm{and} 400$ pA injections in the SP group. ${ }^{*} p<0.01$, compared with control group. In all plots the number of cells in each group is given in

served in the SP group and a smaller effect in the LP and MP groups (Fig. 5). That the largest effect was found in the SP neurons (Fig. 2) suggests that both REM sleep deprivation and nonspecific platform effects influence this response. This is consistent with the data from the LP and MP groups. The rats maintained on LP showed a reduced $R_{\text {in }}$ but little effect on spike frequency adaptation, whereas just the opposite was observed for the MP rats where there was no change in $R_{\text {in }}$ but a profound increase in spike frequency adaptation that was equivalent to the SP group (Fig. 5). 
Table 1. Somatic membrane properties of CA1 pyramidal neurons

\begin{tabular}{|c|c|c|c|c|c|c|c|c|c|c|c|}
\hline Rat & $V_{\mathrm{m}}(\mathrm{mV})$ & $\begin{array}{l}R_{\text {in } \Omega} \\
(\mathrm{M} \& 0 \mathrm{Hgr} ;)\end{array}$ & $\begin{array}{l}\text { AP thresh } \\
(\mathrm{mV})\end{array}$ & $\begin{array}{l}\text { AP ampl } \\
(\mathrm{mV})\end{array}$ & $\begin{array}{l}\text { AP width } \\
\text { (msec) }\end{array}$ & $\begin{array}{l}\text { fAHP } \\
\text { ampl } \\
(\mathrm{mV})\end{array}$ & $\begin{array}{l}\text { fAHP dur } \\
\text { (msec) }\end{array}$ & $\begin{array}{l}\text { mAHP } \\
\text { ampl (mV) }\end{array}$ & $\begin{array}{l}\text { mAHP dur } \\
\text { (msec) }\end{array}$ & $\begin{array}{l}\text { Adapt } \\
\text { (msec) }\end{array}$ & $\begin{array}{l}\text { Cort (ng/ } \\
\mathrm{ml}) n=12\end{array}$ \\
\hline SP (19) & $-62 \pm 1$ & $52 \pm 3^{*}$ & $-51 \pm 1$ & $90 \pm 5$ & $0.8 \pm 0.02$ & $8.9 \pm 2$ & $4.1 \pm 0.1$ & $1.3 \pm 0.2$ & $249 \pm 55$ & $73 \pm 8$ & $211 \pm 33^{*}$ \\
\hline Control (25) & $-63 \pm 1$ & $69 \pm 3$ & $-53 \pm 1$ & $92 \pm 4$ & $0.8 \pm 0.02$ & $8.6 \pm 1$ & $4.8 \pm 0.5$ & $1.2 \pm 0.1$ & $190 \pm 36$ & $43 \pm 4^{*}$ & $87 \pm 21$ \\
\hline
\end{tabular}

$V_{m}$, Resting membrane potential; $R_{\text {in, }}$ input resistance; AP, action potential; thresh, threshold; ampl, amplitude from $V_{m}$, width at half-maximum amplitude; fAHP ampl, fast afterhyperpolarization peak amplitude from $V_{m}$; dur, duration a half-maximum amplitude; mAHP, medium afterhyperpolariztion; adapt, spike frequency adaptation as mean spike interval during last 350 msec of 700 msec current injection; Cort, plasma corticosterone concentration. ${ }^{*} p<0.01$.

Table 2. Dendritic membrane properties of CA1 pyramidal neurons

\begin{tabular}{|c|c|c|c|c|c|c|}
\hline Rat & $V_{\mathrm{m}}(\mathrm{mV})$ & $\begin{array}{l}R_{\text {in } \Omega} \\
(\mathrm{M} \& 0 \mathrm{Hgr} ;)\end{array}$ & $\begin{array}{l}\text { Spike } \\
\text { ampl } \\
(\mathrm{mV})\end{array}$ & $\begin{array}{l}\text { Spike width } \\
\text { (msec) }\end{array}$ & $\begin{array}{l}\text { Spike } \\
\text { boosting } \\
(\%)\end{array}$ & $\begin{array}{l}\text { F-dep } \\
\text { prop } \\
(\%)\end{array}$ \\
\hline $\mathrm{SP}(4)$ & $-69 \pm 2$ & $28 \pm 4^{*}$ & $41 \pm 5$ & $1.4 \pm 0.02^{*}$ & $186 \pm 12$ & $58 \pm 4$ \\
\hline Control (4) & $-71 \pm 1$ & $40 \pm 2$ & $42 \pm 4$ & $2.4 \pm 0.02$ & $190 \pm 20$ & $60 \pm 4$ \\
\hline
\end{tabular}

Dendritic recordings from $250-275 \mu \mathrm{m}$ distant to soma. $V_{\mathrm{m}}$, Resting membrane potential; $R_{\text {in, }}$ input resistance; Spike, dendritic action potential; ampl, amplitude from $V_{m}$, width at half-maximum amplitude; boosting is increase in spike amplitude when paired with a $10-15 \mathrm{mV}$ dendritic depolarization; $\mathrm{F}$-dep prop, frequency dependent propagation as the amplitude of 10 th spike in a train divided by the amplitude of the first spike for $30 \mathrm{~Hz}$ antidromic stimulation. ${ }^{*} p<$ 0.01

Table 3. Schaffer collateral properties

\begin{tabular}{llll}
\hline Rat & fEPSP ampl $(\mathrm{mV})$ & EPSP rise $\tau$ (msec) & PPSP dur (msec) \\
\hline SP $(8,20)$ & $0.58 \pm 0.2$ & $3.5 \pm 0.4$ & $26 \pm 5$ \\
Control $(8,20)$ & $0.61 \pm 0.1$ & $4.0 \pm 0.6$ & $40 \pm 3$ \\
\hline
\end{tabular}

$n=$ (whole cell, field); amplitude at $50 \%$ of maximum; PPF, Paired-pulse facilitation at 50 msec from field recordings; fEPSP, field EPSP.

This suggests that the main impact of long-term immobilization stress on spike firing is mediated through the reduction of $R_{\text {in }}$ (SP and LP groups), whereas the main effect of sleep deprivation (SP and MP) on spiking frequency is produced by an enhanced spike frequency adaptation.

\section{Synaptic plasticity}

These additional treatments also revealed a device-specific effect on hippocampal long-term synaptic plasticity. The magnitude of LTP produced by $100 \mathrm{~Hz}$ tetanic stimulation of Schaffer collateral input was still significantly reduced after $72 \mathrm{hr}$ sleep deprivation using the MP chambers $(25.2 \pm 5.9 \%)$ (Fig. 6), although not to the same extent as the SP group $(6.4 \pm 5.5 \%)$ (Fig. 3$)$. On the other hand, the production of long-term immobilization stress alone (LP) did not have any impact on LTP production in area CA1 $(43.8 \pm 9.4 \%)$ (Fig. 6). Therefore, the deprivation of sleep using the less stressful MP device can still produce a significant impairment of LTP, whereas the production of long-term immobilization stress alone (LP) does not.

\section{Memory}

As was observed for some of the physiological effects described above, there were device-specific effects on hippocampal versus extra-hippocampal memory processes (Fig. 7). Rats that were deprived of sleep for $72 \mathrm{hr}$ by the MP method showed 95\% less freezing than did control rats, indicative of significant and severe memory impairment $(H=16.31$; $\mathrm{df}=2 ; p<0.001)$. Although LP-treated rats also showed decreased freezing, their scores were not significantly different from those of either control or SP rats. Cued memory was not impaired in any of the treatment groups.

Although the above data indicate the presence of both learning deficits and physiological alterations that are specific to particular platform devices, a corticosterone radioimmunoassay indicated that plasma corticosterone levels were similarly elevated in all test groups (Control $87 \pm 21 \mathrm{ng} / \mathrm{ml}$; SP $211 \pm 33 \mathrm{ng} / \mathrm{ml}$; LP $149 \pm 31 \mathrm{ng} / \mathrm{ml}$; MP $180 \pm 31 \mathrm{ng} / \mathrm{ml}$ ). These data suggest that hypothalamic-pituitary-adrenal (HPA) axis-mediated stress was high in all groups. In light of the fact that each device produced different cognitive and physiological alterations, it seems extremely unlikely that any of the observed alterations are simply the result of elevated corticosterone levels and, by extension, HPA-mediated stress.

\section{Discussion \\ Summary}

We have found that $72 \mathrm{hr}$ SD produces severe behavioral deficits that may be linked to particular cellular-level alterations in membrane excitability and synaptic plasticity within the hippocampus. Furthermore, we have performed several experiments that allow us to control for nonspecific methodological issues. Overall, the data may be interpreted to show that primarily REM sleep deprivation inhibits LTP induction, has no effect on LTD, has no effect on $R_{\text {in }}$, increases spike frequency adaptation, elevates circulating corticosterone levels, and dramatically impairs hippocampal-dependent learning task performance. Persistent long-term immobilization stress has no effect on LTP (LTD was not tested), reduces $R_{\text {in }}$ in CA1 cells, does not change adaptation, elevates circulating corticosterone levels, and slightly impairs hippocampal-dependent learning task performance (Fig. 7). Other nonspecific platform effects (e.g., water aversion) do not appear to impact any of the parameters that we have examined.

Together these data indicate that our methods of producing SD induce several robust ion channel and synaptic alterations that overall act to reduce membrane excitability in CA1 pyramidal neurons and inhibit the production of LTP in both dentate granule and CA1 pyramidal neurons. These alterations in the basic membrane and synaptic properties could obviously play an important role in producing the spatial memory deficits observed in the SD rats. Not only could the reduction in LTP inhibit the formation of memory-specific synaptic modifications within the relevant neuronal networks, but also the increased amount of spike frequency adaptation present in CA1 cells could greatly alter spike phase precession, further degrading the temporal encoding of spatial information in the hippocampus (LTP and memory review) (Harris et al., 2002; Mehta et al., 2002). 
It is of interest to note that SD impaired the contextual, but not the cued, aspects of Pavlovian fear conditioning, consistent with a recent study (Dametto et al., 2002). Given that contextual fear conditioning relies on normal hippocampal function (Kim and Fanselow, 1992; Phillips and LeDoux, 1992) and that SD interferes with other types of learning associated with the hippocampus [e.g., the Morris water maze and passive avoidance (Harris et al., 1982; Smith and Rose, 1996)], these behavioral data support the concept that SD disrupts hippocampal function. Conversely, SD did not interfere with the cued aspect of fear conditioning, suggesting that the amygdala is more resistant to the disruptive effects of SD than is the hippocampus.

Voltage-gated ion channel alterations What ion channel alterations might underlie the observed reduction in membrane excitability after SD? The enhanced spike frequency adaptation is presumably the result of an elevation in $I_{\mathrm{AHP}}$ channel activities (Hotson and Prince, 1980; Lancaster and Adams, 1986) but could be in response to alterations in other channel types such as $I_{\mathrm{M}}$ (Storm, 1989). The changes in $R_{\text {in }}$ and dendritic spike duration are most likely the result of an enhanced hyperpolarization-activated $\left(I_{\mathrm{H}}\right)$ channel activity (Maccaferri et al., 1993; Magee, 1998). That dentate granule cells do not appear to have a large $I_{\mathrm{H}}$ component under normal conditions (Stabel et al., 1992; Santoro et al., 2000), and in turn did not show alterations in $R_{\text {in }}$ after SD, supports this hypothesis. Our data therefore suggest that the lack of sleep modifies CA1 neuronal excitability by elevating certain ion-channel activities of which $I_{\mathrm{AHP}}$ and $I_{\mathrm{M}}$ are the most likely candidates. Likewise, sustained immobilization stress appears to produce a similar enhancement of $I_{\mathrm{H}}$ channel activity. Interestingly, various forms of learning have been reported to decrease AHP currents in hippocampal neurons (Moyer et al., 1996; Oh et al., 2001). There are, however, no other reports of stress-related changes in $I_{\mathrm{H}}$, although activity-related alterations in hyperpolarization-activated cyclic nucleotidesensitive cation nonselective channel subunit expression and $I_{\mathrm{H}}$ activity in general have been reported (Chen et al., 2001, Fricker and Johnston, 2001).

\section{Synaptic modification}

What processes are responsible for the impairment of LTP? It is possible that during sleep deprivation there is an increase in synaptic efficacy such that many synapses may be near the LTP saturation point. We feel that this is improbable, because we did not see any facilitation of LTD, as would be expected (Staubli and Lynch, 1990; Wagner and Alger, 1995), and producing LTD before LTP induction did not rescue potentiation. Although it is undoubtedly a contributing factor, the reduced membrane excit-
B

\section{CA1 pyramidal}

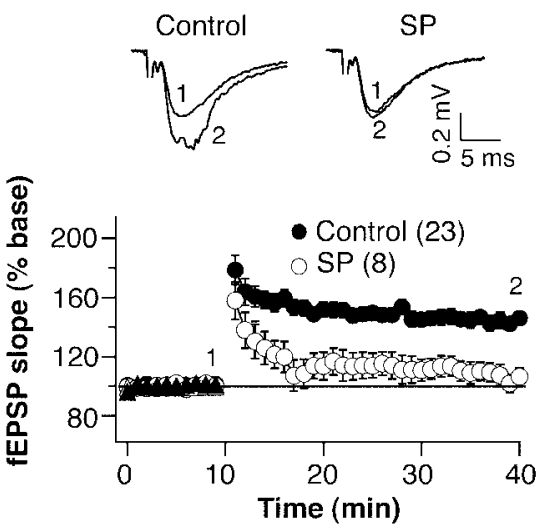

D

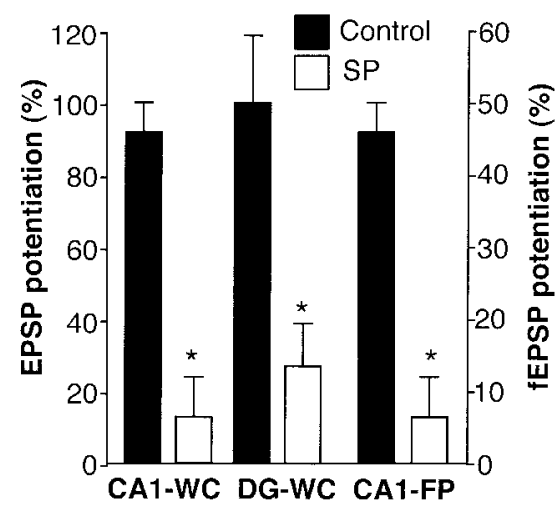

Figure 3. LTP is inhibited in hippocampal slices after sleep deprivation. A, Top, Representative somatic EPSPs recorded in vitro from CA1 cells in response to Schaffer collateral stimulation. Bottom, Normalized averages of EPSP amplitudes (EPSP ampl) from and small platform sleep-deprived rats. Theta-like stimulation of Schaffer collaterals occurred at the 10 min time point.

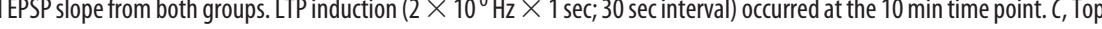
Normalized averages of EPSP amplitudes from control and SP rats. Theta-like stimulation of perforant path occurred at the $10 \mathrm{~min}$ time point. All waveforms are an average of 10 consecutive traces. D, Summary of LTP induction in hippocampal slices (mean \pm SEM) from control and small platform sleep-deprived rats. We calculated potentiation by dividing the average EPSP slopeamplitude at 30 min after tetanus by the baseline average. ${ }^{*} p<0.01$, compared with control group. In all plots the number of cells in each group is given in parentheses. WC, Whole cell; DG, dentate gyrus; FP, field potential.

ability observed after SD is not, by itself, responsible for LTP impairment because comparable numbers of action potentials were produced in all whole-cell recording groups during the induction protocols and LTP is also inhibited in dentate granule cells, where no change in membrane excitability was observed (Fig. 3). Also, differences in the probability of transmitter release do not appear to be a factor because both groups showed similar levels of paired-pulse facilitation. Thus, although there are many potential synaptic alterations to consider, the most obvious place to look would be toward some form of altered postsynaptic NMDA or AMPA receptor function.

\section{Sleep versus nonspecific effects}

As far as synaptic plasticity is concerned, the effects of small platform SD on LTP appear to be mediated primarily by the reduced REM sleep itself. That LTP was normal in the LP group but significantly inhibited in the MP group supports this interpretation. There is, however, a substantial body of evidence indicating that 


\section{$A$
0
0
0
0
$\vdots$
0
$\frac{0}{0}$
$\frac{0}{0}$
0
0}
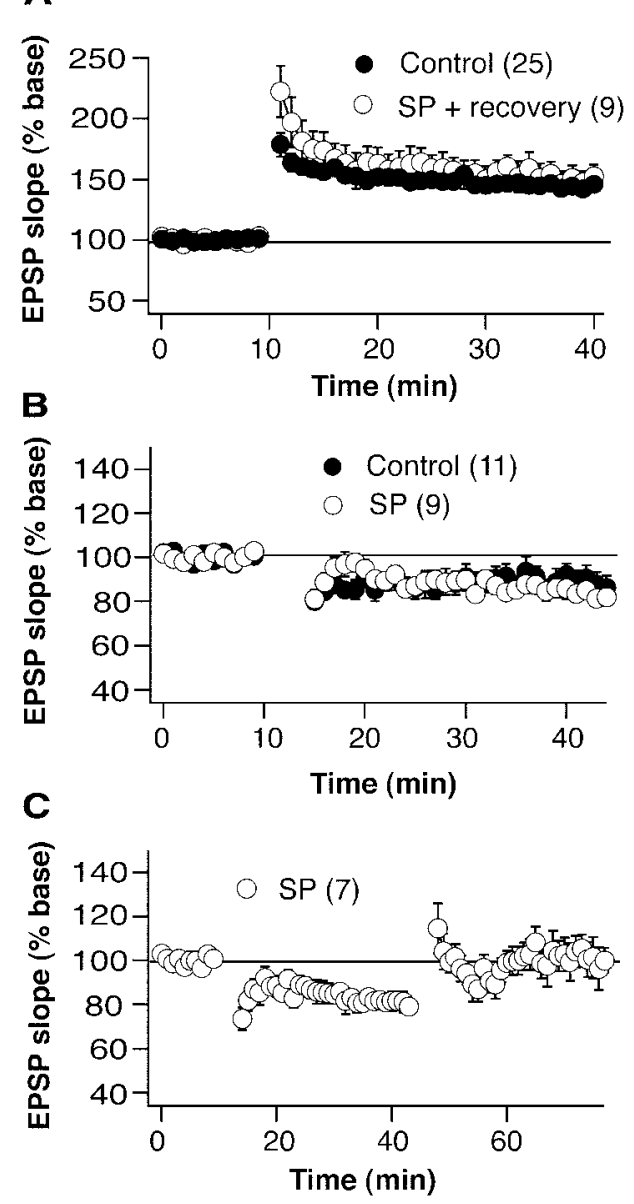

Figure 4. LTP is recoverable and LTD is unaffected. $A$, Twenty-four hour recovery after $72 \mathrm{hr}$ single platform sleep-deprivation restores LTP to control levels. Tetanus, $100 \mathrm{~Hz}(2 \times 1 \mathrm{sec}, 30$ sec interval), occurred at the $10 \mathrm{~min}$ time point. $B, \mathrm{LTD}$ is unaffected by $72 \mathrm{hr}$ of small platform sleep deprivation. LTD induction $(5 \mathrm{~min} \times 3 \mathrm{~Hz}$ ) occurred at the $10 \mathrm{~min}$ time point. C, Giving LTD before LTP induction does not rescue LTP in rats sleep deprived on the small platform. LTD induction occurred at the $10 \mathrm{~min}$ time point, and LTP induction occurred at the $45 \mathrm{~min}$ time point. Graphs represent grouped data showing normalized fEPSP slope. In all plots the number of cells in each group is given in parentheses.

short-term or intermittent, long-term immobilization stress alters LTP (Xu et al., 1998; Pavlides et al., 2002) and learning and memory (Luine et al., 1994; de Quervain et al., 1998), with this effect being mediated mainly through the HPA stress axis (Xu et al., 1998) and mimicked by modulations in circulating corticosterone (Pavlides et al., 1993; de Quervain et al., 1998) (but see Bramham et al., 1998; Kim et al., 2001). The data presented here indicate that there may be some possibility for adaptation to the immobilization stress and elevated corticosterone levels produced during this sustained amount of time. These observations are in line with reports stating that sleep actually enhances plasticity (Frank et al., 2001) and with others showing that long-term immobilization stress does not impair developmental synaptic plasticity, whereas sleep deprivation does (Schaffery et al., 2002). Furthermore, the fact that corticosterone levels were consistently elevated across all manipulations, whereas the behavior and cell physiology were affected differentially, indicates that elevated circulating corticosterone is not in itself the causative factor of the observed alterations. Moreover, both acute (Blank et al., 2002) and chronic (Conrad et al., 1999; Sandi et al., 2001) restraint stress as well as exogenous corticosterone (Cordero and Sandi,
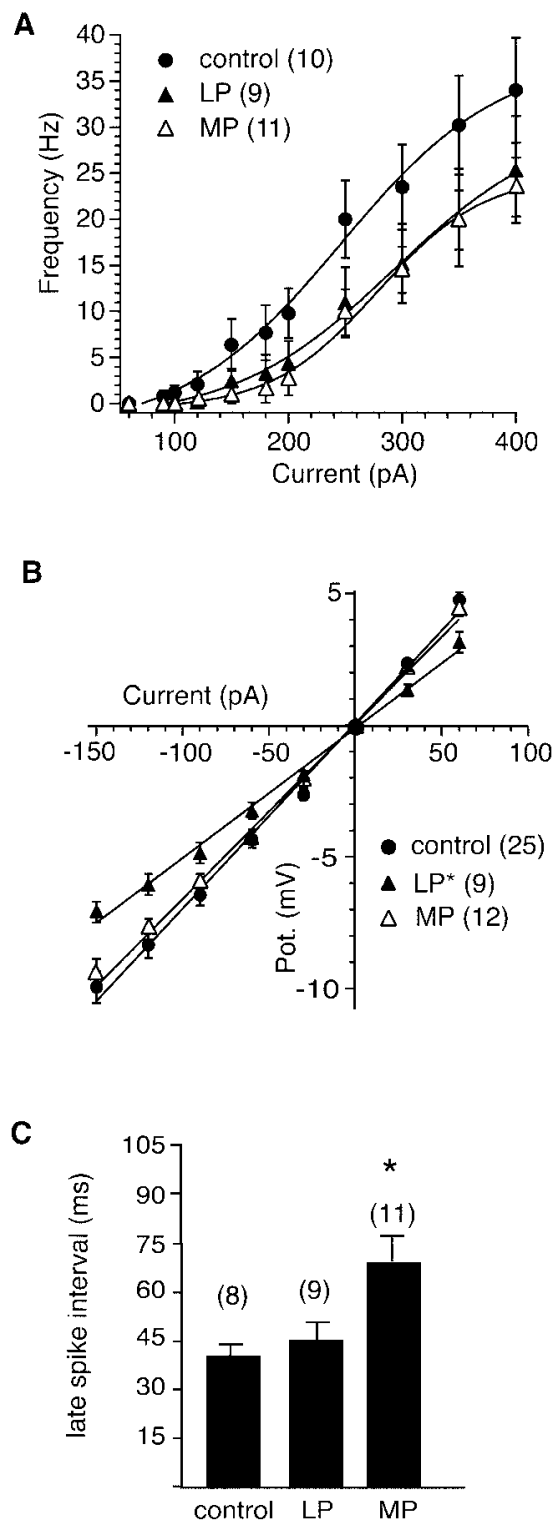

Figure 5. Neuronal excitability shows treatment-specific effects. A, Summary frequencycurrent plot shows that firing is reduced in both the LP and MP groups, compared with controls. $B$, Summary current-voltage plots show that $R_{\text {in }}$ is reduced in neurons from the LP group but not in neurons from the MP group. C, Summary plots of adaptation (mean interval for spikes in the final 350 msec of the current step) show that the MP group has enhanced adaptation compared with the control and $L P$ groups. To normalize for the differences in $R_{\text {in }}$, mean intervals were calculated from $350 \mathrm{pA}$ injections in the control and MP groups and $400 \mathrm{pA}$ injections in the LP group. Significantly different $(p<0.05)$ groups are as indicated. In all plots the number of cells in each group is given in parentheses.

1998) have been shown to augment contextual memory rather than to impair it, as was observed in the present studies. This strongly suggests that the deficiencies in contextual memory found in the present study are the result of SD and not the result of stressful aspects of the platform-over-water method.

\section{Conclusion}

The present findings demonstrate that $3 \mathrm{~d}$ of primarily REM sleep deprivation produce severe behavioral and cellular abnormalities that primarily originate with the lack of REM sleep itself. This is not to say that our method of sleep deprivation or sleep deprivation per se is devoid of additional stressors; in fact, recent evi- 
A

$$
\text { Control }
$$
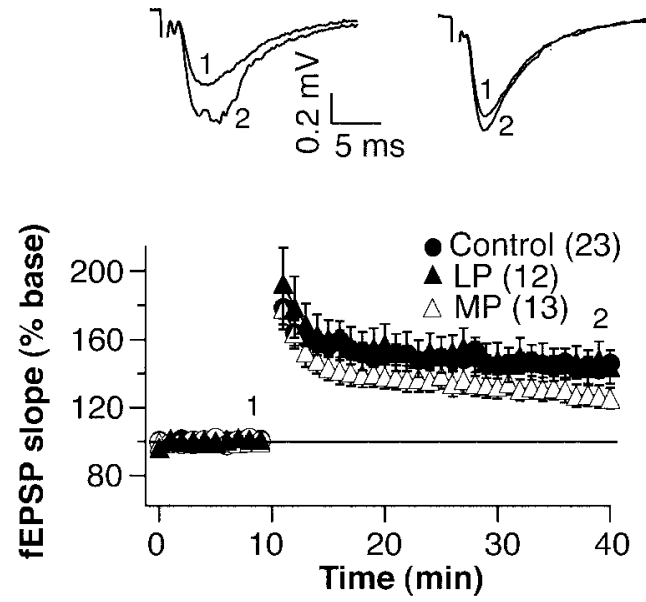

B

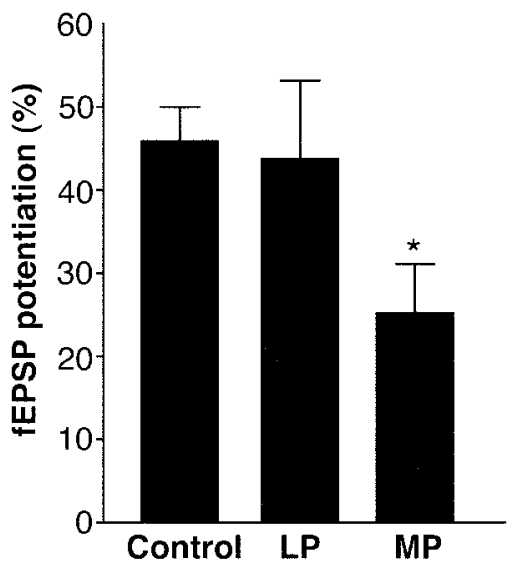

C

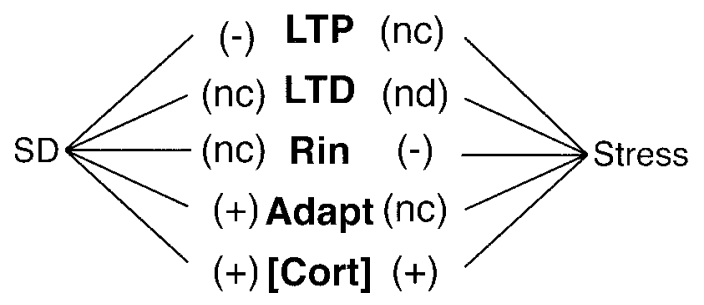

Figure 6. A, Top, Representative CA1 field potentials recorded in vitro from control and multiple platform sleep-deprived rats after Schaffer collateral stimulation. Bottom, Grouped data showing normalized field EPSP slope from control, MP, and LP groups. LTP induction $(2 \times$ $10^{\circ} \mathrm{Hz} \times 1$ sec; 30 sec interval) occurred at the 10 min time point. $B$, Summary of EPSP slope LTP (mean \pm SEM) for control, MP, and LP groups. We calculated potentiation by dividing the average EPSP slope at 30 min after tetanus by the average baseline EPSP slope. ${ }^{*} p<0.05$, compared with control group. In all plots the number of cells in each group is given in parentheses. C, Summary sketch showing the differential effects of sleep deprivation versus stress on various synaptic and membrane properties of CA1 hippocampal cells. nd, Not determined; nc, not changed; Rin, input resistance.

dence suggests that stress may be an intrinsic component of sleep deprivation (Meerlo et al., 2002). Nevertheless, we can state with some degree of certainty that depriving rats of quality REM sleep leads to specific reductions in membrane excitability and synaptic plasticity, all of which could diminish the ability of these animals to perform certain learning and memory tasks.

\section{References}

Blank T, Nijholt I, Eckart K, Spiess J (2002) Priming of long-term potentiation in mouse hippocampus by corticotrophin-releasing factor and

\section{A. Contextual Memory}

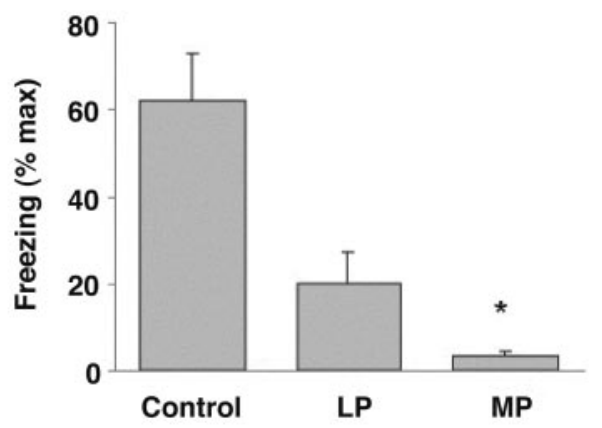

B. Cued Memory

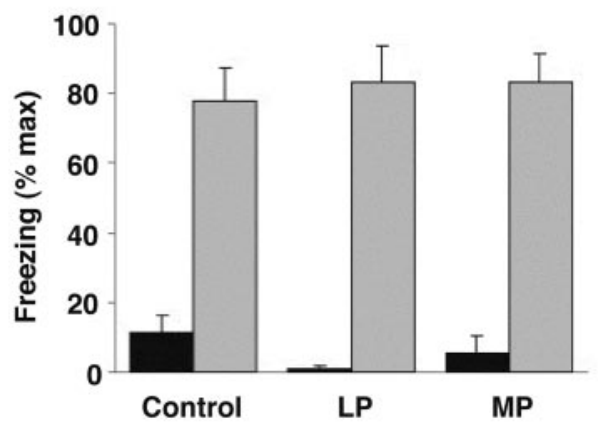

Figure 7. Effects of $72 \mathrm{hr}$ SD on hippocampus-mediated $(A)$ and amygdala-mediated $(B)$ memory. Y-axes show the mean ( \pm SEM) amount of freezing as percentage of maximum $(\%$ max) possible for each group. $A$, Freezing in the context in which tone-shock pairings occurred $24 \mathrm{hr}$ before test was significantly $\left({ }^{*} p<0.001\right)$ reduced in rats sleep deprived for $72 \mathrm{hr}$ by the MP method $(n=9)$. Freezing in rats placed on the LP for $72 \mathrm{hr}(n=7)$ was intermediate between that of control $(n=9)$ and MP rats and not significantly different from either group. (Data were collapsed over the 6 min test period, during which no tones or shocks were delivered.) $B$, Freezing in a novel environment before (black bars) and after (gray bars) presentation of the cue (tone) that had been paired previously with shock was equivalent among all treatment groups. No shock was presented during this test.

acute stress: implications for hippocampus-dependent learning. J Neurosci 22:3788-3794.

Bliss TVP, Collingridge GL (1993) A synaptic model of memory: long-term potentiation in the hippocampus. Nature 361:31-39.

Bramham CR, Southard T, Ahlers ST, Sarvey JM (1998) Acute cold stress leading to elevated corticosterone neither enhances synaptic efficacy nor impairs LTP in the dentate gyrus of freely moving rats. Brain Res 789:245-255.

Buzsaki G (1998) Memory consolidation during sleep: a neurophysiological perspective. J Sleep Res 7:17-23.

Chen K, Aradi I, Thon N, Eghbal-Ahmadi M, Baram TZ, Soltesz I (2001) Persistently modified h-channels after complex febrile seizures convert the seizure-induced enhancement of inhibition to hyperexcitability. Nat Med 7:331-337.

Coenen AML, Van Luijtelaar ELJM (1985) Stress induced by three procedures of deprivation of paradoxical sleep. Physiol Behav 35:501-504.

Conrad CD, Magarinos AM, LeDoux JE, McEwen BS (1999) Repeated restraint stress facilitates fear conditioning independently of causing hippocampal CA3 dendritic atrophy. Behav Neurosci 113:902-913.

Cordero MI, Sandi C (1998) A role for brain glucocorticoid receptors in contextual fear conditioning: dependence upon training intensity. Brain Res 786:11-17.

Dametto M, Suchecki D, Bueno OFA, Moreira KM, Tufik S, Oliveria MGM (2002) Social stress does not interact with paradoxical sleep deprivationinduced memory impairment. Behav Brain Res 129:171-178.

de Quervain DJ-F, Roozendaal B, McGaugh JL (1998) Stress and glucocor- 
ticoids impair retrieval of long-term spatial memory. Nature 394:787-790.

Frank MG, Issa NP, Stryker MP (2001) Sleep enhances plasticity in the developing visual cortex. Neuron 30:275-287.

Fricker D, Johnston D (2001) Plastic changes in intrinsic excitability associated with long-term synaptic potentiation in CA1 pyramidal neurons. Soc Neurosci Abstr 27:501.13.

Graves L, Pack A, Abel T (2001) Sleep and memory: a molecular perspective. Trends Neurosci 24:237-243.

Harris KD, Henze DA, Hirase H, Leinekugel X, Dragoi G, Czurko A, Buzsaki G (2002) Spike train dynamics predicts theta-related phase precession in hippocampal pyramidal cells. Nature 417:738-741.

Harris PF, Overstreet DH, Orbach J (1982) Disruption of passive avoidance memory by REM sleep deprivation: methodological and pharmacological considerations. Pharmacol Biochem Behav 17:1119-1122.

Hotson JR, Prince DA (1980) A calcium-activated hyperpolarization follows repetitive firing in hippocampal neurons. J Neurophysiol 43:409-419.

Karni A, Tanne D, Rubenstein BS, Askenasy JJM, Sagi D (1994) Dependence on REM sleep of overnight improvement of a perceptual skill. Science 265:679-682.

Kim JJ, Fanselow MS (1992) Modality-specific retrograde amnesia of fear. Science 256:675-677.

Kim JJ, Lee HJ, Han J-S, Packard MG (2001) Amygdala is critical for stressinduced modulation of hippocampal long-term potentiation and learning. J Neurosci 21:5222-5228.

Lancaster B, Adams PR (1986) Calcium-dependent current generating the afterhyperpolarization of hippocampal neurons. J Neurophysiol 55:1268-1282.

Louie K, Wilson MA (2001) Temporally structured replay of awake hippocampal ensemble activity during rapid eye movement sleep. Neuron 29:145-156.

Luine V, Villegas M, Martinez C, McEwan BS (1994) Repeated stress causes reversible impairments of spatial memory performance. Brain Res 639:167-170

Maccaferri G, Mangoni M, Lazzari A, DiFrancesco D (1993) Properties of the hyperpolarization-activated current in rat hippocampal CA1 pyramidal cells. J Neurophysiol 69:2129-2136.

Magee JC (1998) Dendritic hyperpolarization-activated currents modify the integrative properties of hippocampal CAl pyramidal neurons. J Neurosci 18:7613-7624.

Magee JC, Johnston D (1997) A synaptically controlled, associative signal for Hebbian plasticity in hippocampal neurons. Science 275:209-213.

Mandai O, Guerrien A, Sockeel P, Dujardin K, Leconte P (1989) (1989) REM sleep modifications following a Morse code learning session in humans. Physiol Behav 46:639-642.

Maquet P (2001) The role of sleep in learning and memory. Science 294:1048-1052.

Meerlo P, Koehl M, van der Borght K, Turek FW (2002) Sleep restriction alters the hypothalamic-pituitary-adrenal response to stress. J Neuroendocrinol 14:397-402.

Mehta MR, Lee AK, Wilson MA (2002) Role of experience and oscillations in transforming a rate code into a temporal code. Nature 417:741-746.

Moyer JR, Thompson LT, Disteroft JF (1996) Trace eyeblink conditioning increases CA1 excitability in a transient and learning-specific manner. J Neurosci 16:5536-5546.
Oh MM, Gamelli AE, Wu WW, Sametsky E, Disterhoft JF (2001) Morris water maze learning enhances neuronal excitability of CA1 hippocampal pyramidal neurons in rats. Soc Neurosci Abstr 27:921.1.

Pace-Schott EF, Hobson JA (2002) The neurobiology of sleep: genetics, cellular physiology and subcortical networks. Nat Rev Neurosci 3:591-605.

Pavlides C, Watanabe Y, McEwan BS (1993) Effects of glucocorticoids on hippocampal long-term potentiation. Hippocampus 3:183-192.

Pavlides C, Nivon LG, McEwan BS (2002) Effects of chronic stress on hippocampal long-term potentiation. Hippocampus 12:245-257.

Phillips RG, LeDoux JE (1992) Differential contribution of amygdala and hippocampus to cued and contextual fear conditioning. Behav Neurosci 106:274-285.

Sandi C, Merino JJ, Cordero MI, Touyarot K, Venero C (2001) Effects of chronic stress on contextual fear conditioning and the hippocampal expression of the neural cell adhesion molecule, its polysialylation, and L1. Neuroscience 102:329-339.

Santoro B, Chen S, Luthi A, Pavlidis P, Shumyatsky GP, Tibbs GR, Siegelbaum SA (2000) Molecular and functional heterogeneity of hyperpolarization-activated pacemaker channels in the mouse CNS. J Neurosci 20:5264-5275.

Schaffery JP, Sinton CM, Bissette G, Roffwarg HP, Marks GA (2002) Rapid eye movement sleep deprivation modifies expression of long-term potentiation in visual cortex of immature rats. Neuroscience 110:431-443.

Siegel JM (2001) The REM sleep-memory consolidation hypothesis. Science 294:1058-1063.

Skaggs WE, McNaughton BL (1996) Replay of neuronal firing sequences in rat hippocampus during sleep following spatial experience. Science 271:1870-1873.

Smith C (1995) Sleep states and memory processes. Behav Brain Res 69:137-145.

Smith C, Lapp L (1986) Prolonged increases in both PS and number of REMS following a shuttle avoidance task. Physiol Behav 36:1053-1057.

Smith C, Rose GM (1996) Evidence for a paradoxical sleep window for place learning in the Morris water maze. Physiol Behav 59:93-97.

Stabel J, Ficker E, Heinemann U (1992) Young CA1 pyramidal cells of rats, but not dentate gyrus granule cells, express a delayed inward rectifying current with properties of $\mathrm{I}_{\mathrm{Q}}$. Neurosci Lett 135:231-234.

Staubli U, Lynch G (1990) Stable depression of potentiated synaptic responses in the hippocampus with $1-5 \mathrm{~Hz}$ stimulation. Brain Res 513:113-118.

Stern W (1971) Acquisition impairments following rapid eye movement sleep deprivation in rats. Physiol Behav 7:345-352.

Stickgold R, Hobson JA, Fosse R, Fosse M (2001) Sleep, learning, and dreams: off-line memory processing. Science 294:1052-1057.

Storm JF (1989) An after-hyperpolarization of medium duration in rat hippocampal pyramidal cells. J Physiol (Lond) 409:171-190.

Wagner JJ, Alger BE (1995) GABAergic and developmental influences on homosynaptic LTD and depotentiation in rat hippocampus. J Neurosci 15:1577-1586.

Wilson MA, McNaughton BL (1994) Reactivation of hippocampal ensemble memories during sleep. Science 265:676-679.

Xu L, Holscher C, Anwyl R, Rowan MJ (1998) Glucocorticoid receptor and protein/RNA synthesis-dependent mechanisms underlie the control of synaptic plasticity by stress. Proc Natl Acad Sci USA 95:3204-3208. 